\title{
PERCEPÇÃO SOBRE ATRIBUTOS DE SUSTENTABILIDADE EM UM VAREJO SUPERMERCADISTA
}

\author{
PERCEPTION REGARDING THE ATTRIBUTES OF SUSTAINABILITY IN A RETAIL \\ SUPERMARKET \\ PERCEPCIÓN SOBRE LOS ATRIBUTOS DE SUSTENTABILIDAD EN UN COMERCIO MINORISTA \\ SUPERMERCADISTA
}

\section{RESUMO}

Os selos e certificados são uma resposta do varejo à necessidade dos consumidores de maior monitoramento da qualidade e segurança dos alimentos. Existem diversos tipos de selos encontrados no varejo; alguns são específicos para o atributo relacionado à origem do produto e outros, ainda, atestam diversas características intrínsecas e extrínsecas. Entre os selos dos produtos comercializados por uma rede supermercadista no Brasil, está o Garantia de Origem (GO). Para avaliar a percepção dos consumidores, entrevistaram-se 120 clientes em supermercados na região de Campinas e Piracicaba/SP, que tivessem produtos GO. Foram identificados, por meio de análise fatorial, quatro dimensões relevantes: segurança alimentar; qualidade intrínseca do produto; sistema de produção diferente e verificação do governo. Já em relação aos atributos sustentabilidade e origem, valores como prestígio, credibilidade e respeito foram considerados relevantes. O artigo apresenta contribuições nos campos metodológico e teórico, auxiliando a melhor compreensão dessas percepções dos consumidores sobre esses atributos.

PALAVRAS-ChaVE Marca própria, marketing, cadeia meio-fim, análise fatorial, rastreabilidade.

Christiano França da Cunha chfcunha@unimep.br

Professor do Programa de Pós-Graduação em Administração da Universidade Metodista de Piracicaba - Piracicaba - SP, Brasil

Eduardo Eugênio Spers edespers@gmail.com

Professor do Departamento de Administração da Escola Superior de Propaganda e Marketing - São Paulo - SP, Brasil

Decio Zylbersztajn dezylber@usp.br

Professor da Faculdade de Economia, Administração e Contabilidade da Universidade de São Paulo - São Paulo - SP, Brasil

Abstract The labels and certificates are a response from the retail to consumer's needs for enhanced monitoring of quality and food safety. There are several types of labels found in retail, some are specific to the attribute related to the origin of the product and others attest various intrinsic and extrinsic characteristics. Among labels of products marketed by a supermarket network in Brazil is the Guarantee of Origin (G.0). In order to assess the perception of consumers, 120 customers were interviewed in supermarkets in the region of Campinas and Piracicaba-SP, that had GO products. By means of factor analysis, four important dimensions were identified: food safety; intrinsic quality of product; different production system; and governmental verification. In relation to the origin and sustainability attributes, values such as prestige, credibility and respect were considered relevant. The paper presents contributions in the methodological and theoretical fields, helping a better comprehension of these consumers' perceptions about these attributes.

keywords Private label, Marketing, Means-end chains, Factor analysis, Traceability.

Resumen Los sellos y certificados son una respuesta del comercio minorista a la necesidad de los consumidores de un mayor control de calidad y seguridad de los alimentos. Existen diversos tipos de sellos encontrados en el comercio minorista; algunos son específicos para el atributo relacionado a la origen del producto y otros, todavía, atestan diversas características intrínsecas e extrínsecas. Entre los sellos de los productos comercializados por una red supermercadista en el Brasil, está el de la Garantía de Origen (GO). Para evaluar la percepción de los consumidores, se hizo entrevistas con 120 clientes en supermercados en la región de Campinas y Piracicaba/SP, en donde había productos GO. Fueron identificados, por medio de análisis factorial, cuatro dimensiones relevantes: seguridad alimentar; calidad intrínseca del producto; sistema de producción diferente y averiguación del gobierno. Ya en relación a los atributos sustentabilidad y origen, valores como prestigio, credibilidad y respecto fueron considerados relevantes. El artículo presenta contribuciones en los campos metodológico y teórico, ayudando a una mejor comprensión de esas percepciones de los consumidores sobre eses atributos.

Palabras clave Marca propia, marketing, cadena medios-fines, análisis factorial, trazabilidad. 


\section{INTRODUÇÃo}

Nos últimos anos, o tema sustentabilidade vem sendo divulgado nas mídias impressa, escrita e falada. Com isso, o consumidor vem sendo constantemente exposto a esse conceito, o que pode influenciar a sua decisão de compra de produtos.

Mas o termo "sustentabilidade" apresenta um alto grau de complexidade, pois, na verdade, é um conjunto de atributos sociais, econômicos e ambientais que alguns produtos devem ter para serem assim classificados. Esses atributos podem variar desde a proteção ao meio ambiente até uma maior consciência social dos agentes produtivos desses bens.

Para esclarecer melhor qual a real percepção dos consumidores ao se depararem com um produto sustentável, os autores entrevistaram 120 consumidores em supermercados localizados na região de Campinas e Piracicaba/SP, para saber como esses clientes interpretavam a mensagem de que esse produto era sustentável.

Para isso, foram escolhidos produtos em estabelecimentos varejistas que tivessem uma garantia de sua procedência, os quais são identificados com o uso de um selo chamado "Garantia de Origem". Esses produtos foram selecionados por possuírem uma rastreabilidade de atributos ligados à preocupação com o meio ambiente e com os aspectos sociais dos fornecedores desses alimentos vendidos nessa determinada rede de varejo (ZYLBERSZTAJN, SPERS, CUNHA, 2009). Portanto, duas importantes vertentes da sustentabilidade (a ambiental e a social) estão presentes nessa averiguação de atributos.

Dessa forma, observa-se que esse controle dos atributos e a forma como isso pode influenciar a percepção dos consumidores são importantes temas a serem abordados, sendo estes mais detalhados no próximo tópico deste artigo.

\section{REFERENCIAL TEÓRICO}

Nesta parte do texto, observam-se os referenciais teóricos sobre atributos de segurança, origem e sustentabilidade, assim como sobre o selo do varejo estudado.

\section{Atributos de segurança, origem e sustentabilidade}

Segundo Peter e Olson (1999), os atributos de um produto são o principal estímulo que influencia o consumidor em sua tomada de decisão de compra e são avaliados em função dos valores, crenças ou experiências passadas do indivíduo. Portanto, os atributos são vistos como propriedades ou características intrínsecas ao produto, mensuráveis e observáveis (ESPARTEL e SLONGO, 1999); podem ser tangíveis (concretas, físicas, objetivas) ou intangiveis (abstratas, benéficas, subjetivas) (LEFKOFF-HAGIUS e MANSON, 1990) e de relevante importância na escolha entre alternativas.

Observa-se que os alimentos possuem vários atributos, os quais podem ser classificados de acordo com suas qualidades presentes, podendo ser estas extrínsecas ou intrínsecas. No primeiro caso, esse tipo se caracteriza por possuir atributos que tenham fácil percepção pelo consumidor, pois podem ser vistos externamente no produto. Já no caso das intrínsecas, esses atributos precisam de instrumentos, como selos, certificados, rotulagens ou marcas, para que possam ser facilmente percebidos pelos consumidores. Portanto, os consumidores usam indicadores extrínsecos (ex.: nome de marca) na procura de valores intrínsecos (RICHARDSON, DICK e JAIN, 1994; PEREIRA, 2001). Sua percepção está altamente relacionada à confiança nesses instrumentos (SPERS, 2003). Por isso, devido a essa necessidade de confiança, esses produtos são chamados de bens de crença (DARBY e KARNI, 1973). O Quadro 1 mostra alguns exemplos desses atributos e suas classificações quanto a esse critério mencionado.

O conhecimento desses atributos faz-se importante, principalmente, porque estes norteiam a decisão de compra, conforme proposto em Grunert e outros (1996) (Figura 1). Nesse modelo ou simplificação de uma compra geral por um alimento, existem dois momentos distintos, antes e depois da compra. Isso implica dizer que um atributo ou o conjunto deles pode ser avaliado nesses dois momentos. Antes, atributos que promovem a percepção de qualidade podem ser intrínsecos ou extrínsecos. A avaliação sobre o atributo pode ser baseada nas suas características técnicas, no custo, na comunicação ou mensagem explicitada. Esses estímulos geram a intenção de compra e a expectativa pelo conjunto de atributos de um produto. Depois da compra, atributos relacionados ao preparo e à experimentação do atributo tornam-se relevantes.

É certo que alguns outros atributos ganham força e importância no sistema agroalimentar, como sustentabilidade e origem, mas a questão da qualidade e segurança evidencia e caracteriza bem os aspectos que desafiam a gestão por atributos nesse segmento.

Sob o enfoque quantitativo, denominamos o atributo de segurança alimentar como o abastecimento 
adequado de uma determinada população (TEIXEIRA, 1981). Esse atributo é, em geral, obtido com o desenvolvimento do país, derivado do aumento da renda familiar e de uma oferta adequada e substancial de alimentos, seja pela produção interna ou pelas importações. Esse atributo está relacionado a outros como a qualidade e a quantidade de nutrientes ingeridos por uma determinada população.

A segurança do alimento ou o atributo segurança, visto sob o enfoque qualitativo da garantia de o consumidor adquirir um alimento com atributos de qualidade, entre os quais se destacam os atributos ligados à sua saúde (SPERS, 2003), é uma preocupação crescente devido aos diversos escândalos de contaminação e adulteração em alimentos (Quadro 2). Além disso, no- vos processos até então de difícil compreensão, como a irradiação e a transgenia de alimentos, reforçam as dúvidas e os riscos percebidos pelo consumidor.

Para tentar levantar e rastrear esses atributos de segurança alimentar, assim como de sustentabilidade e aspectos sociais, inspeções realizadas por estabelecimentos credenciados nacional ou internacionalmente vêm se transformando em rotina no setor agroalimentar. Além desse tipo de inspeção, empresas varejistas podem também realizar vistorias a fim de levantar e mapear todas as características almejadas em seus fornecedores, por meio de listas de atributos/características desejados, como acontece no caso dos produtos com o selo "Garantia de Origem" (ZYLBERSZTAJN, SPERS, CUNHA, 2009).

\section{Quadro 1 - Atributos dos alimentos e suas classificações}

\begin{tabular}{|c|c|c|}
\hline & Qualidade extrínseca & Qualidade intrínseca \\
\hline & Preço & Danos ao meio ambiente \\
\hline Atributos dos alimentos & Aparência & Ausência de aditivos e/ou conservantes \\
\hline & Cor & Ausência de resíduos químicos \\
\hline & Tamanho & Valor nutricional \\
\hline
\end{tabular}

Fonte: adaptado de SPERS, 2003.

\section{Quadro 2 - Definições sobre o atributo segurança em alimentos}

\begin{tabular}{|c|c|c|c|}
\hline Autor & Definição & Ano & $\begin{array}{l}\text { Visão quanto aos atributos da } \\
\text { segurança do alimento }\end{array}$ \\
\hline FAO & $\begin{array}{l}\text { "é a garantia em se consumir um alimento isento de resíduos que } \\
\text { prejudiquem ou causem danos à saúde" }\end{array}$ & 2010 & Não presença de determinados atributos. \\
\hline $\begin{array}{l}\text { Smith e } \\
\text { outros }\end{array}$ & $\begin{array}{l}\text { "segurança não é uma mercadoria que os consumidores de alimen- } \\
\text { tos podem ir ao supermercado para comprar... antes, segurança é } \\
\text { uma característica das mercadorias e serviços que eles compram, } \\
\text { e ela é uma característica extremamente cara e em alguns casos } \\
\text { impossível de ser acessada" }\end{array}$ & 1998 & $\begin{array}{l}\text { Segurança não é um conjunto de atributos, } \\
\text { mas o próprio atributo avaliado pelo consu- } \\
\text { midor. Complementa-se com a dificuldade } \\
\text { de mensuração do atributo. }\end{array}$ \\
\hline $\begin{array}{l}\text { Henson e } \\
\text { Traill }\end{array}$ & $\begin{array}{l}\text { "é o inverso do risco alimentar - a probabilidade de não sofrer } \\
\text { nenhum dano pelo consumo de um alimento" }\end{array}$ & 1993 & Atributo que tem evidência é o risco. \\
\hline $\begin{array}{l}\text { Hobbs e } \\
\text { Kerr }\end{array}$ & $\begin{array}{l}\text { "aquisição, pelo consumidor, de alimentos de boa qualidade, livres } \\
\text { de contaminantes de natureza química (pesticidas), biológica (orga- } \\
\text { nismos patogênicos), física (vidros e pedras), ou de qualquer outra } \\
\text { substância que possa acarretar problemas à sua saúde" }\end{array}$ & 1992 & $\begin{array}{l}\text { Relaciona atributos de características } \\
\text { químicas, biológicas e físicas. }\end{array}$ \\
\hline
\end{tabular}

Fonte: adaptado de SPERS, 2003. 
Dessa forma, cada produto é visto como um conjunto de atributos, com capacidades diferentes de prestar os benefícios anunciados e satisfazer uma necessidade. As características dos produtos oferecidos são comparadas com as especificações e padrões dos consumidores (AMARAL e NIQUE, 2000). Os critérios de escolha são os benefícios desejados na compra e no consumo, que são expressos em forma de atributos preferidos, segundo a lógica da metodologia da cadeia meio- fim (means and ends).

Nota-se que a cadeia meio-fim tem a função de entender a estrutura cognitiva que os consumidores apresentam ao observar que as informações dos produtos são retidas em suas memórias em diferentes ní-

\section{Figura 1 - Modelo genérico da decisão por um alimento e seus atributos}

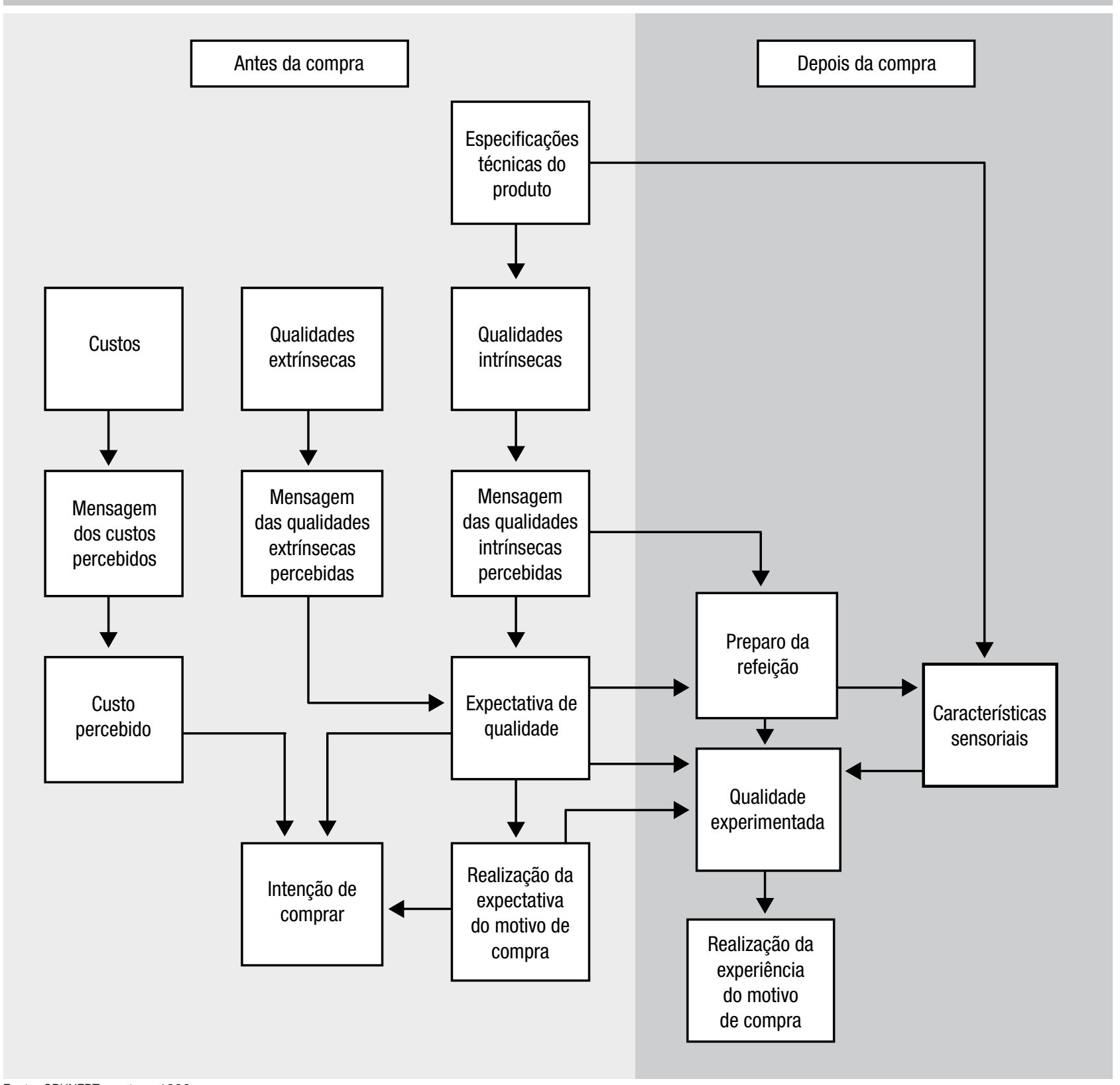


veis de abstração (COHEN, 1979; MYERS e SHOCKER, 1981; OLSON e REYNOLDS, 1983; YOUNG e FEIGEN, 1975). Entre esses diversos níveis, os mais simples são os atributos dos produtos e os mais complexos são os seus valores e/ou payoff dos produtos para os consumidores (ZEITHAML, 1988).

Dessa forma, há uma "cadeia de benefícios", a qual ilustra como um produto está conectado por meio dela a um conceito chamado de "payoff emocionais" (YOUNG e FEIGEN, 1975). Sua sequência é a seguinte:

$$
\begin{gathered}
\text { Produtos } \rightarrow \text { Benefícios funcionais } \rightarrow \text { Benefícios } \\
\text { práticos } \rightarrow \text { Payoff emocionais. }
\end{gathered}
$$

Para observar como isso se aplica aos conceitos de sustentabilidade, uma pesquisa com consumidores em estabelecimentos varejistas foi realizada. Os resultados encontrados e suas análises estão presentes e detalhados no próximo tópico.

\section{O selo do varejo estudado (G0)}

O GO nasceu baseado no papel coordenador e informador que os supermercados modernos exercem, simultaneamente do campo ao consumidor final: para implantar o GO, foi realizada, pelo varejo, uma pesquisa com consumidores antes de lançar o selo, e selecionaram-se os cinco atributos mais importantes, que formaram a base do GO.

O produto deve primar por: (1) ser seguro e saudável; (2) ter sabor autêntico; (3) ter aspecto visual superior; (4) ser ecologicamente correto e (5) ser socialmente correto.

Para o varejo em questão, todo progresso econômico deve ser desenvolvido sobre bases ecológicas sustentáveis, ou seja, respeitando as características ecológicas originais da região de origem. Realizar o tratamento da água utilizada antes de retorná-la ao ambiente, repor nutrientes do solo, evitar assoreamento de rios, são algumas das preocupações que o produtor deve ser incentivado a adotar. Em relação à responsabilidade social, adequadas condições de trabalho são pré-requisitos para a qualidade de vida dos colaboradores envolvidos com a produção. O modelo apregoa que todos os trabalhadores dos produtores certificados sejam maiores de idade e registrados formalmente. Os agricultores são estimulados a realizar projetos sociais nas suas comunidades, cujas características são por eles definidas. Em suma, o selo GO é um compromisso com a sociedade.
Os selos e certificados são respostas à necessidade sentida pelos consumidores de maior monitoramento da qualidade e segurança dos alimentos. Existem diversos tipos de selos, alguns são específicos para o atributo relacionado à origem do produto e outros atestam características intrínsecas e extrínsecas.

Entre os produtos comercializados pela rede, estão os que levam o selo GO, para o qual a organização segue o conceito de ser um selo que informa ao cliente os cuidados adicionais de qualidade, quando comparados aos produtos tradicionais.

O processo de credenciamento do produto GO inicia-se no contato com produtores promissores e um convite para o credenciamento. Baseadas em uma primeira visita de auditoria, cujo objetivo é explicar os fundamentos do programa e do seu funcionamento, sugestões e orientações são realizadas com base em uma visita a campo feita pelo auditor, que funciona como um agente extensionista especializado. Avaliação de planilhas de controle do uso de defensivos, deposição de embalagens, estoque de produtos de sanidade vegetal, respeito às nascentes e recursos hídricos em geral, estrutura de apoio aos trabalhadores, incluindo sanitários nas áreas de trabalho, estão entre os aspectos trabalhados na visita de avaliação.

As exigências variam de produto para produto. Além de características físicas, como tamanho e superfície de danos, o produto GO exige diversos cuidados, como a correta aplicação de defensivos, boas práticas de fabricação, bem-estar dos funcionários, preservação do meio ambiente, entre outros. No caso dos peixes, o animal é transportado vivo, abatido e etiquetado com o selo GO no próprio Centro de Distribuição do varejo.

São realizadas auditorias periódicas pelo auditor externo. Os itens que fazem parte da checagem da auditoria são: (a) localização, histórico e manejo da área; (b) tratos culturais da exploração; (c) tratamento fitossanitário; (d) packing house (embalagem; (e) rastreabilidade; (f) meio ambiente; (g) aspectos sociais; (h) amostras para laboratório e (i) outros comentários. Cada item do conjunto que compõe cada aspecto é avaliado por uma nota que varia de 1 a 5 ( $1=$ inaceitável, $2=$ precisa mudar, $3=$ aceitável, $4=$ satisfatório e 5 = excelente). A seguir, são listados alguns dos requisitos avaliados nos aspectos meio ambiente e social (checklist):

Meio ambiente:

- A propriedade tem legalizada sua área de reserva florestal? 
- Estão preservados e protegidos na propriedade as matas ciliares e seus mananciais de água?

- Há na propriedade problemas aparentes de erosão de solo?

- Os locais de preparo das caldas para as aplicações fitossanitárias apresentam risco para a contaminação do meio ambiente?

- Os resíduos do processamento do produto no packing house trazem risco para o meio ambiente?

- Há algum tratamento dos resíduos do packing house visando à preservação do meio ambiente?

- Visando contribuir para a conscientização da população e incutir valores de responsabilidade ambiental, a empresa participa de projetos de conservação de áreas protegidas?

- A empresa participa de programas de reflorestamento em matas ciliares ou outras áreas que tenham sido indevidamente eliminadas na propriedade?

Social:

- A propriedade tem todos os seus funcionários registrados e faz regularmente o recolhimento de seus encargos?

- Há funcionários menores de idade trabalhando na propriedade?

- Visando aprimorar o nível de seus recursos humanos, a propriedade tem programa de erradicação do analfabetismo entre seus funcionários?

- A propriedade oferece aos seus empregados algum auxílio para educação dos filhos?

- A empresa oferece benefícios a seus empregados, tais como: plano de saúde extensivo aos dependentes, seguro de vida, cesta básica, alojamento e refeições na propriedade, transporte, entre outros?

- A empresa faz algum apoio em Programa de Responsabilidade Social na região em que está inserida, como doações financeiras e de materiais para instituições ou contratação de funcionários deficientes?

Uma vez considerado apto, o produtor é convidado a assinar contrato segundo o qual o varejo se compromete a ser o comprador preferencial e o fornecedor, em cumprir as exigências do selo.

\section{METODOLOGIA}

Foi realizada uma pesquisa com uma amostra de 120 entrevistados, entre consumidores e potenciais consu- midores dos produtos GO. Esses entrevistados foram escolhidos por conveniência entre as pessoas que frequentemente realizam compras em supermercados na região de Campinas e Piracicaba.

O símbolo do GO foi apresentado ao respondentes. Estes foram indagados sobre sua concordância em relação a algumas afirmações. As opções de resposta basearam-se em uma escala Likert de 4 pontos $(1=$ discorda totalmente, $2=$ discorda, $3=$ concorda e $4=$ concorda totalmente).

Por meio do modelo de cadeias meio-fim, foi possível mapear os valores considerados como relevantes pelos consumidores. A fim de aprofundar ainda mais essa análise dos atributos percebidos, um grupo reduzido desses consumidores entrevistados também avaliou a importância em relação (1) ao produto GO e (2) ao tema sustentabilidade.

\section{RESULTADOS E DISCUSSÃO}

Assume-se uma escala intervalar das respostas obtidas (discordo totalmente $=1$; discordo $=2$; concordo $=3$ e concordo totalmente $=4$ ), ou seja, a distância entre o discordo totalmente (1) e discordo (2) é exatamente 1. Para parametrizar a média entre 0 e 1 dividiu-se o valor por 4 criando-se assim um índice de concordância. Os resultados desse índice encontram-se na Tabela 1.

$\mathrm{Na}$ Tabela 1, as perguntas com o índice de concordância superior a 0,70 , indicam um alto grau de concordância, estão com uma marcação verde. Por esses números, observa-se que os produtos GO são vistos pelos consumidores entrevistados claramente como mais seguros; mais caros; são verificados por uma certificadora; com mais qualidade; e respeitam o meio ambiente.

As perguntas com índices entre 0,60 e 0,69 indicam que os consumidores veem os produtos GO de uma forma menos clara, como uma "jogada" de marketing; que podem ser adulterados; têm mais frescor; contêm agrotóxicos; que não há como garantir totalmente a origem; mas são totalmente confiáveis; e são únicos desse supermercado.

Com um índice de concordância inferior a 0,60, as perguntas mostram uma percepção confusa em algumas questões, nas quais observa-se que os consumidores interpretam os produtos GO como não confiáveis, pois não conhecem como são produzidos, sendo isso um 
contraste com a resposta de totalmente confiáveis, mas de acordo com a questão de que não há como garantir totalmente a origem; não têm diferença significativa; são mais saborosos; são orgânicos; são verificados pelo governo; produzidos apenas por produtores de pequeno porte; e são mais fáceis de serem produzidos.

A fim de agruparem-se as questões abordadas em alguns fatores principais de observação e consideração dos consumidores, foram elaboradas algumas análises fatoriais. Mas, para verificar se seria interessante uma análise fatorial nessas questões, observou-se se a medida de Kaiser-Meyer-Olkin (KMO) inicial é superior a 0,50, que de fato é, pois esse índice é de 0,66, indicando que a análise fatorial é uma medida favorável a ser adotada para a explicação dessas perguntas. Para a obtenção da melhor análise fatorial, foram retiradas dessas referidas análises algumas questões, segundo os seguintes critérios: (a) questões com uma baixa variância de resposta, ou seja, com uma variância inferior a 0,50; e (b) questões ligadas de modo semelhante a dois ou mais fatores e com variância pequena $(0,50$ $0,60)$. O resultado da análise fatorial obtida por esses critérios está exposto na Tabela 2.

Observa-se que essa análise fatorial teve um KMO de 0,74 , indicando um bom índice para análise fatorial. Além disso, a variância total explicada foi de 61,15\%, ou seja, $61,15 \%$ da variância dessas questões foram explicados por esses fatores.

Como visto na Tabela 2, essas questões podem ser agrupadas em quatro fatores, segundo os seus valores mostrados. A denominação dos fatores é a seguinte: Fator 1 = Segurança alimentar; Fator 2 = Qualidade intrínseca do produto; Fator 3 = Sistema de produção diferente e Fator 4 = Verificação do governo.

Observa-se que, entre esses quatro fatores, o de maior destaque e maior número de questões (6) é o fator de segurança alimentar, que, sozinho, explica $23,60 \%$ da variância das questões estudadas e também apresenta altos índices correlação na Tabela 2. Isso pode indicar

\section{Tabela 1 - Índice de concordância das 120 entrevistas na amostra estudada}

\begin{tabular}{|c|c|}
\hline Pergunta & $\begin{array}{c}\text { Índice } \\
\text { concordância }\end{array}$ \\
\hline São mais seguros que os outros & 0,74 \\
\hline São mais caros que os outros & 0,74 \\
\hline São verificados por uma certificadora independente & 0,73 \\
\hline Têm mais qualidade que os outros & 0,71 \\
\hline Respeitam o meio ambiente & 0,70 \\
\hline São só uma "jogada" de marketing do supermercado & 0,67 \\
\hline Podem ser adulterados ou fraudados & 0,65 \\
\hline Têm mais frescor & 0,64 \\
\hline Contêm agrotóxicos & 0,63 \\
\hline Não há como garantir totalmente a origem & 0,61 \\
\hline São totalmente confiáveis & 0,61 \\
\hline São únicos, outros supermercados não têm & 0,61 \\
\hline Não são confiáveis, pois não conheço como são produzidos & 0,58 \\
\hline Em geral, não apresentam diferenças significativas em relação aos outros & 0,56 \\
\hline São mais saborosos que os outros & 0,56 \\
\hline São orgânicos & 0,53 \\
\hline São verificados pelo governo & 0,52 \\
\hline São produzidos somente por produtores de pequeno porte & 0,50 \\
\hline São mais fáceis de serem produzidos & 0,49 \\
\hline
\end{tabular}




\section{Tabela 2 - Análise fatorial das questões remanescentes na amostra estudada com os critérios acima citados}

\begin{tabular}{|l|c|c|c|}
\hline \multicolumn{1}{|c|}{ Questões perguntadas } & Fator 1 & Fator 2 & Fator 3 \\
\hline São mais seguros que os outros & 0,74 & \\
\hline São totalmente confiáveis & 0,68 & \\
\hline Têm mais qualidade que os outros & 0,65 & \\
\hline Não há como garantir totalmente a origem & $-0,65$ & \\
\hline Podem ser adulterados ou fraudados & $-0,63$ & \\
\hline São verificados por uma certificadora independente & 0,52 & \\
\hline São orgânicos & & 0,75 \\
\hline São mais saborosos que os outros & & 0,74 \\
\hline Têm mais frescor & & 0,71 \\
\hline São mais caros que os outros & & 0,62 \\
\hline São únicos, outros supermercados não têm & & \\
\hline Não são confiáveis, pois não conheço como são produzidos & & 0,79 \\
\hline São verificados pelo governo & & 0,74 \\
\hline
\end{tabular}

\section{Figura 2 - Cadeia meio-fim de garantia de origem}

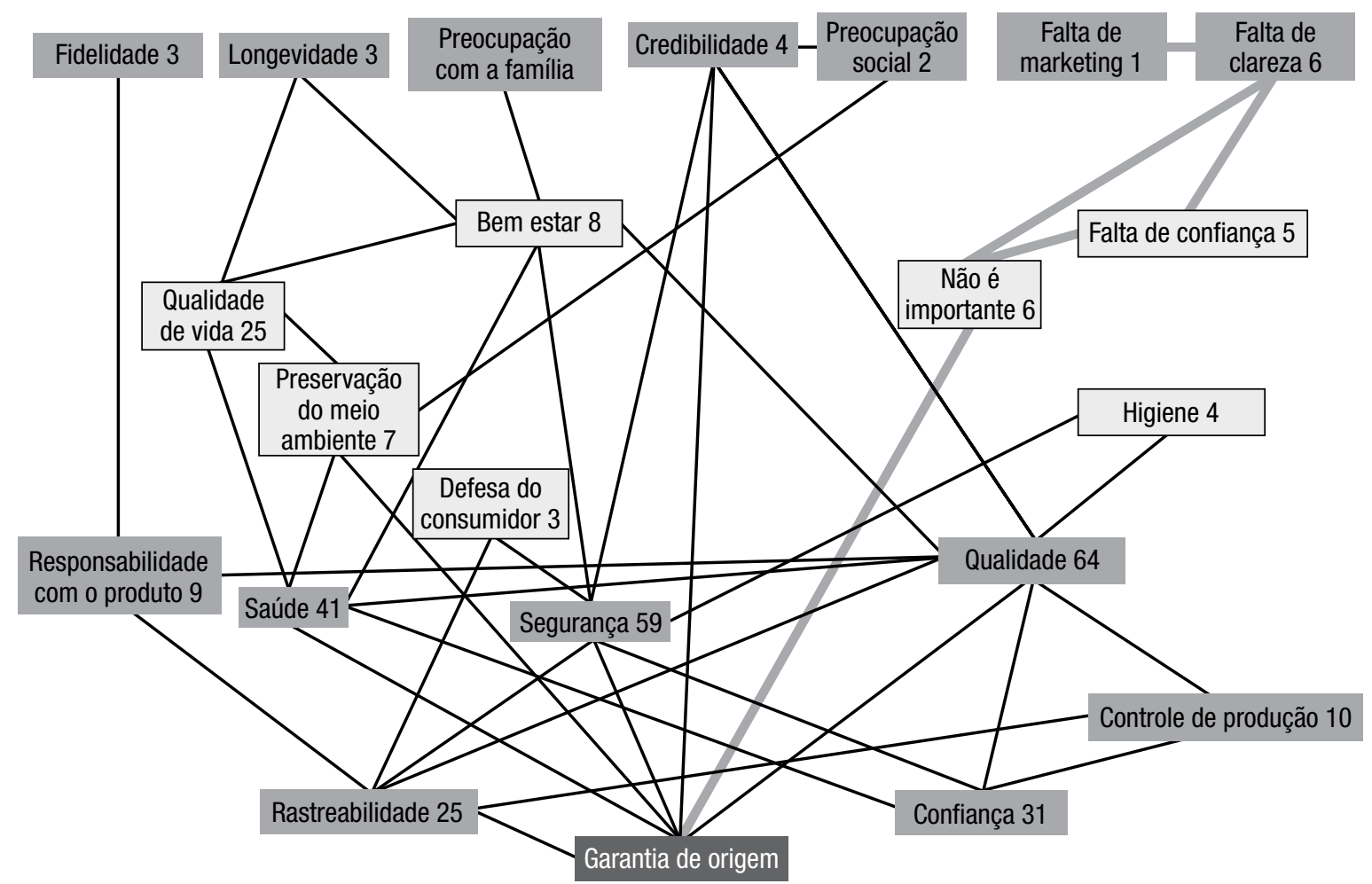


que os consumidores levam mais em conta, ao caracterizarem o GO, o fator de segurança alimentar.

Com relação ao fator "Qualidade intrínseca" do produto, ele explica $17,84 \%$ da variância e é o segundo maior destaque desses fatores, apresentando também altos índices de correlação na Tabela 2. O fator "Sistema de produção diferente" indica que o consumidor tem a consciência de que os produtos GO são produzidos de maneira distinta dos convencionais, mas isso pode ter o lado negativo de não dar segurança para o comprador sobre a confiabilidade do produto, por não saber como é produzido. Esse fator é responsável pela explicação de 10,32\% da variância total e também apresenta altos índices de correlação na Tabela 2. O último fator, a verificação do governo para esses produtos, é o menor deles, com apenas uma questão, mas com uma alta correlação, como se pode observar na Tabela 2 .
Seu poder de explicação da variância total é de 9,35\%. Além disso, 85\% das cargas fatoriais foram classificadas com muito boas ou excelentes, ou seja, superiores a 0,55 (COMREY, 1973; ROZZET e DEMO, 2010).

Por meio do modelo de cadeias meio-fim, foi possível mapear os valores considerados como relevantes pelos consumidores. As figuras 2 e 3 ilustram os resultados obtidos. O número ao lado de cada valor representa a quantidade de respostas recebidas.

Observa-se, na Figura 2, que os atributos de qualidade, segurança e saúde são, respectivamente, os mais citados. Isso ressalta, mais uma vez, a imagem que os consumidores têm desses produtos, como algo diferenciado, principalmente em questões de segurança alimentar.

Além dessa evidente preocupação com a segurança alimentar, outra preocupação de grande destaque

\section{Figura 3 - Cadeia meio fim de sustentabilidade}

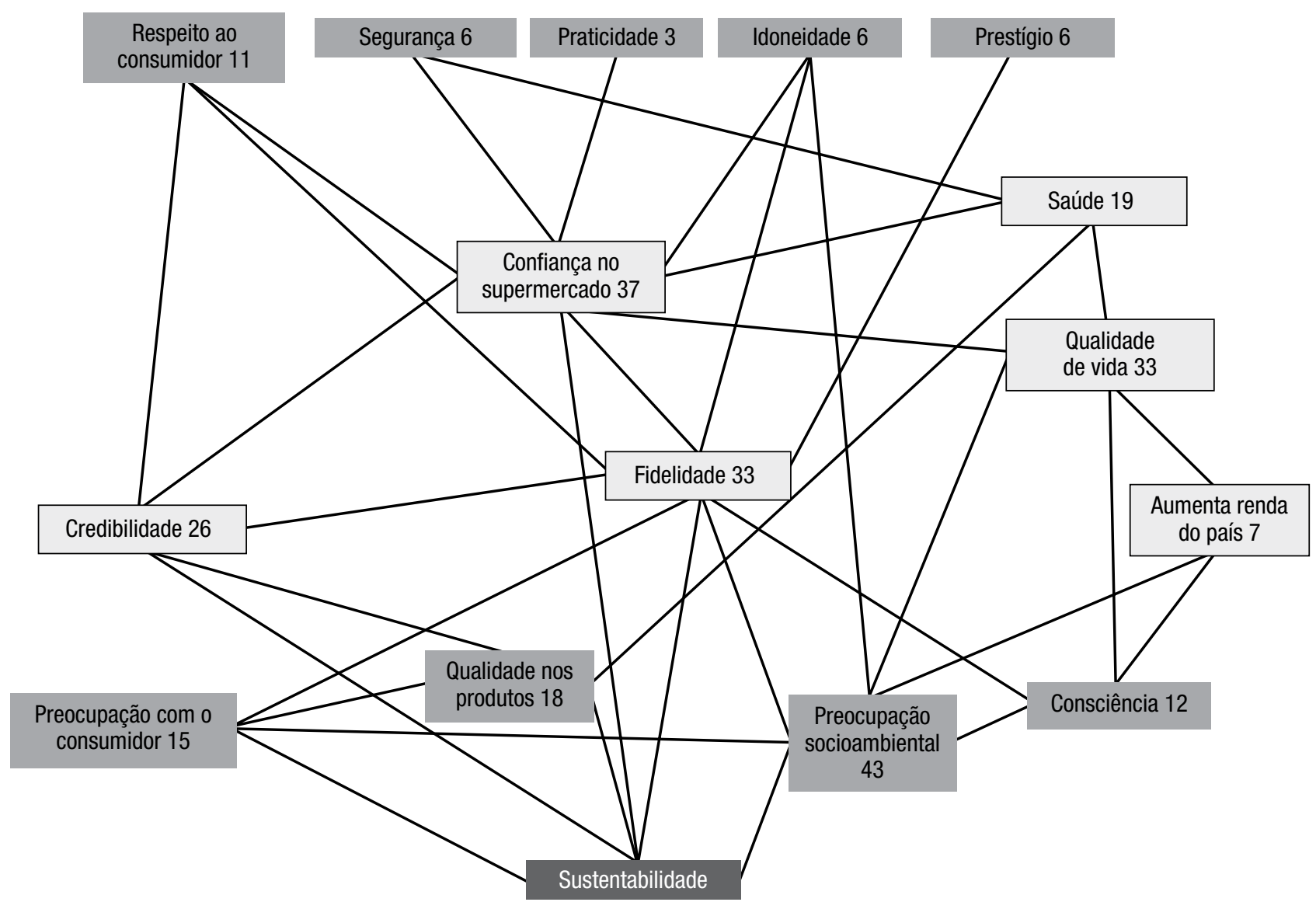


desses consumidores é com relação ao aspecto socioambiental, como pode ser visto na Figura 3, sendo esta a principal citação na cadeia meio-fim do tema sustentabilidade.

\section{CONSIDERAÇõES FINAIS}

No presente trabalho, observou-se como os atributos de sustentabilidade, origem e segurança alimentar, cada vez mais ressaltados nas mídias impressa, escrita e falada, podem afetar a decisão de compra dos consumidores.

Os resultados indicam que o consumidor tem claro que o GO é um produto diferenciado, com um apelo maior para segurança alimentar e preservação do meio ambiente; e que também é certificado por um órgão independente.

Nota-se que os atributos ligados a sustentabilidade e segurança alimentar são reconhecidos nos produtos estudados. Resultados disso são mostrados tanto nas análises de concordâncias como na análise fatorial realizada.

Novos estudos podem explorar os métodos de análise de cadeia meiofim, avaliando outros atributos importantes na decisão do consumidor, como a produção orgânica, fair trade, origem (local food), entre outros. Em relação às questões de concordância (escala Likert), trabalhos futuros podem validar, com base nas dimensões aqui encontradas, uma escala de decisão de compra sobre atributos de origem, sustentabilidade e segurança em supermercados.

Estudos que comparem diferentes regiões, como diferentes países, podem captar a influência do ambiente institucional e dos aspectos culturais nos atributos aqui analisados. Outras pesquisas podem comparar os resultados com a compra realizada em outros tipos de varejo, inclusive o virtual.

\section{REFERÊNCIAS}

AMARAL, B. L; NIQUE, W. M. E-commerce: atributos determinantes na utilização da internet como canal de compra. In: ENCONTRO NACIONAL DA ASSOCIAÇÃO NACIONAL DOS PROGRAMAS DE PÓS-GRADUAÇÃO EM ADMINISTRAÇÃO, 24, 2000, Florianópolis. Anais. Florianópolis: ANPAD, 2000.
COHEN, J. B. The structure of products attributes: defining attributes dimensions for planning and evaluation. In: SHOCKER, A. D. (Ed) Analytic approaches to product and marketing planning. Boston: Cambridge, 1979. p. 239-256.

COMREY, A. L. A first course in factor analysis. 2nd. ed. New York: Academic Press, 1973.

DARBY, M. R; KARNI, E. Free competition and the optimal amount of fraud. Journal of Law and Economics, v. 16. n. 1, p. 67-88, 1973.

ESPARTEL, L. B; SLONGO, L. A. Atributos de produto e motivação de compra no mercado jornalístico do Rio Grande do Sul. In: ENCONTRO NACIONAL DA ASSOCIAÇÃO NACIONAL DOS PROGRAMAS DE PÓS-GRADUAÇÃO EM ADMINISTRAÇÃO, 23, 1999, Foz do Iguaçu. Anais. Foz do Iguaçu: Anpad, 1999.

FAO. Food Aid Organization. Red de Cooperación Técnica sobre Sistemas de Vigilancia Alimentaria y Nutricional (Red SISVAN). Roma, 2009. Disponível em: http://www.rlc.fao. org/redes/sisvan. Acesso em 29.07.2010.

GRUNERT, K. G; BAADSGAARD, A; LARSEN, H. H; MADSEN, T. K. Market orientation in food and agriculture. Massachussetts: Kluwer Academic Publishers, 1996.

HENSON, S; TRAILL, B. The demand for food safety: market imperfections and the role of government. Food Policy, v.18, n.2, p. 152-162, 1993.

HOBBS, J. E; KERR, W. A. Cost of monitoring food safety and vertical coordination in agribusiness: what can be learned from the British Food Safety Act 1990? Agribusiness an International Journal, v. 8, n. 6, p. 575-584, 1992.

LEFKOFF-HAGIUS, R; MANSON, C. H. The role of tangible and intangible attributes in similarity and preference judgment. Advances in Consumer Research, v. 17, n.1, p. 135-143, 1990.

MYERS, J. H; SHOCKER, A. D. The nature of product-related attributes, Research in Marketing, v. 5, n.1, p. 211-236, 1981.

OLSON, J. C; REYNOLDS, T. J. Understanding consumers' cognitive structures: implication for advertising strategy, advertising and consumer psychology. Boston: Lexington Books, 1983. 
PEREIRA, I. Marcas de supermercado. RAE-Revista de Administração de Empresas, v. 41, n. 1, p. 16-27, 2001.

PETER, J. P; OLSON, J. C. Consumer behavior and marketing strategy. 5th ed. Boston: Irwin Mcgraw-Hill, 1999.

RICHARDSON, P; DICK, A; JAIN, A. K. Extrinsic and intrinsic cue effects on perception of store brand quality. Journal of Marketing, v. 58, n. 4, p. 28-36, 1994.

ROZZET, K; DEMO, G. Desenvolvimento e validação fatorial da escala de relacionamento com cliente (ERC). RAE-Revista de Administração de Empresas, v. 50, n. 4, p. 383-395, 2010.

SMITH, M. E. e outros. Sales loss determination in food contamination incidents: an application to milk bans in Hawaii. American Journal of Agriculture Economics, v. 73, n. 3, p. 513-520, 1998.

SPERS, E. E. Mecanismos de regulação da qualidade e segurança em alimentos. 2003. 136 p. Tese de Doutorado em Administração, Faculdade de Economia, Administração e Contabilidade, Universidade de São Paulo, São Paulo, 2003.

TEIXEIRA, I. Segurança alimentar ameaçada. Conjuntura Econômica, v. 35, n. 12, p.109-113, dez. 1981.

YOUNG, S; FEIGEN, B. Using the benefit chain for improved strategy formulation. Journal of Marketing, v. 39, n.3, p. $72-74,1975$.

ZEITHAML, V. A. Consumer perceptions of price, quality, and value: a means-end model and synthesis of evidence. Journal of Marketing, v. 52, n.3, p. 2-22, 1988.

ZYLBERSZTAJN, D; SPERS, E. E; CUNHA, C. F da. Quality line Carrefour. In: ANNUAL WORLD SIMPOSIUM OF INTERNATIONAL FOOD \& AGRIBUSINESS MANAGEMENT ASSOCIATION (IAMA), 19, 2009, Budapest. Annals. Budapest: IAMA, 2009. 